\author{
기분 장애 소아 청소년 환자에서 자살 행동, \\ 공격 행동과 인지기능과의 관계 \\ 윤희준 · 오윤혜 · 정유숙 \\ 성균관대학교 의과대학 삼성서울병원 정신건강의학교실
}

\title{
Suicidal Behavior, Violent Behavior, and Neurocognitive Function in Child and Adolescent Mood Disorder Patients
}

\author{
Hee Joon Yoon, M.D., Yunhye Oh, M.D., and Yoo Sook Joung, M.D., Ph.D. \\ Department of Psychiatry, Samsung Medical Center, Sungkyunkwan University School of Medicine, Seoul, Korea
}

\begin{abstract}
Objectives: The aim of this study was to examine the association between current suicidal or violent behavior and deficits of specific neurocognitive variables in child and adolescent inpatient samples diagnosed with mood disorder.

Methods: A retrospective review of the charts of mood disorder patients hospitalized at Samsung Medical Center between April 2004 and April 2015 was conducted. Child and adolescent patients aged between 10 and 18 years old and those who finished neurocognitive function testing during their hospitalization were included. Among them patients whose full scale IQ was between 85 and 115 were selected $(\mathrm{N}=111)$. Participants were first divided into two age-groups-group $\mathrm{Y}(10 \leq$ age $\leq 15$, N=54) and group $\mathrm{O}(16 \leq \mathrm{age} \leq 18, \mathrm{~N}=57)$-because neurocognitive function test tools were different according to age [Wechsler Intelligence Scale for Children (WISC) for 10 to 15-year-old patients, Wechsler Adult Intelligence Scale (WAIS) for 16 to 18 -year-old patients]. They were then divided according to their suicidal or violent behavior-non suicidal/violent group (NG), suicidal group (SG), violent group (VG), and both suicidal/violent group (BG). The Child Behavior Checklist (CBCL) was checked for measurement of participants' behavior and the Gordon Diagnostic System was checked for measurement of their attention efficiency. Kruskal-Wallis Test and Tukey test was used to determine the differences in neurocognitive function between groups.

Results: O-SG patients showed lower scores on the comprehension subscale of WAIS-III than O-NG patients $\left(\chi^{2}=8.454\right.$, $\mathrm{p}=.015)$. O-VG patients showed lower scores on the block design subscales of WAIS than O-SG patients $\left(\chi^{2}=7.496, p=.024\right)$. Y-VG patients showed higher scores in aggressive behavior, externalizing problems, and total problems scores of CBCL.

Conclusion: This study showed relationship between specific neurocognitive deficits and suicidal or violent behavior. These relationships were significant in relatively older adolescents.
\end{abstract}

KEY WORDS: Mood Disorder · Child and Adolescent · Suicidal Behavior · Violent Behavior · Neurocognitive Function.

\author{
서 론 \\ 우울 장애는 소아에서 2-3\%, 청소년에서는 $8 \%$ 에 이르기 \\ Date received: November 13, 2015 \\ Date of revision: December 18, 2015 \\ Date accepted: December 21, 2015 \\ Address for correspondence: Yoo Sook Joung, M.D., Ph.D., Department of \\ Psychiatry, Samsung Medical Center, Sungkyunkwan University School of \\ Medicine, 81 Irwon-ro, Gangnam-gu, Seoul 06351, Korea \\ Tel: +82.2-3410-3589, Fax: +82.2-3410-0050 \\ E-mail: yschoung@skku.edu
}

까지 보고될 정도로 소아 청소년에서 흔한 질환이며,1) 최근 연구에 따르면 양극성 장애 또한 소아 청소년에서 $2 \%$ 정도로 높게 보고되고 있다. ${ }^{2}$ 입원을 요하는 소아 청소년 환자에서 도 기분 장애는 흔한 질환 중 하나이며, ${ }^{3}$ 특히 자살 행동과 공격 행동이 있는 경우 정신과 병동에 입원하게 되는 경우가 많다.) 이전 연구들에서 정신과적 질환이 청소년기의 자살 시도의 중요한 위험 인자이며 그중에서도 우울 장애, 양극성 장애를 포함한 기분 장애가 자살의 가장 중요한 위험 인자임 이 알려져 왔다. ${ }^{5)}$ 또한, 한국에서 시행된 연구에서도 정신과 입원 소아 청소년 환자 중 자살 시도자에서 기분 장애가 있 
는 경우가 다른 정신과적 장애가 있는 경우에 비해 유의미하 게 많았다.)

소아 청소년 환자에서 보이는 자살 행동이나 공격 행동은 입원의 원인이 될 뿐만 아니라 환자 자신의 생활 및 가족, 학 교, 지역사회에도 부정적인 영향을 미치게 된다.) 이에 이러 한 자살 행동이나 공격 행동과 연관된 요인들을 찾기 위한 노력이 있어 왔으며 그중 신경인지학적인 측면에서 자살 행 동, 공격 행동을 설명하려는 노력이 이루어져 왔다. 이전 연구 에서 소아 청소년기, 혹은 성인기 인지 장애가 이후의 자살 위험도를 높인다는 보고가 있었으며, ${ }^{8)}$ 자살 행동이 주의 집 중(attention), 기억(memory), 작업 기억 능력(working memory)의 저하와 관련이 있다는 보고가 있었으나' 아직까지 자 살 행동과 특정 인지기능 사이의 명확한 관계는 밝혀지지 않 았고, 특히 소아 청소년을 대상으로 한 연구는 아직까지 부 족한 실정이다. ${ }^{10)}$ 또, 기존 연구에서는 집행 기능(executive function)의 한 부분인 작업 기억 능력의 저하가 공격성과 연 관이 있다는 보고 ${ }^{11)}$ 및 공간 능력(spatial ability)의 저하와 반사회적 행동과 관련이 있다는 보고가 있어 왔으나, ${ }^{12,13)}$ Stanford 등 ${ }^{14}$ 의 연구에서는 집행 기능과 공격 행동과의 명 확한 관계를 규명하지 못하기도 하였고, 몇몇 리뷰에서는 공 격 행동과 신경인지기능의 관계가 분명치 않다고 보고하고 있어 ${ }^{15,16)}$ 공격 행동과 인지기능과의 관계 역시 명확히 밝혀 져 있다고 보기는 어렵다. 또한, 많은 연구가 성인 대상으로 이루어져 왔기에, ${ }^{17)}$ 소아 청소년 대상의 연구는 아직까지 부 족한 실정이다.

소아 청소년의 기분 장애와 인지기능과의 관계에 대해서는 몇몇 연구가 이루어져 왔는데, 소아 청소년 우울 장애 환자 들은 언어적 기억(verbal memory) 능력의 저하를 보인다는 연구와, ${ }^{18)}$ 소아 청소년 양극성 장애 환자들이 언어적 기억, 주의 집중력, 집행 기능, 작업 기억, 시각 공간적 기억(visuospatial memory) 등의 영역에서 기능 저하를 보인다는 연구 ${ }^{19,20)}$ 등이 보고되고 있다.

위에 살펴본 바와 같이 자살 행동, 공격 행동과 인지기능 과의 관계에 대한 연구와, 기분 장애와 인지기능과의 관계에 대한 연구는 있어 왔지만, 아직까지 명확하게 밝혀지지 않은 부분이 많으며, 소아 청소년 기분 장애 환자군 내에서 자살 행동 및 공격 행동에 따른 인지 기능의 차이가 있는지에 대 한 연구는 아직까지 거의 이루어지지 않았다.

이에 본 연구에서는 일차적으로 기분 장애 소아 청소년 환 자에서 자살 행동, 공격 행동과 특정 인지 기능과의 관련이 있는지를 알아보고자 하였다. 이차적으로는 아동 행동 평가 척도(Korean Child Behavior Checklist, K-CBCL)의 각 항 목과 자살, 공격 행동이 관련이 있는지 알아봄으로써 소아
청소년 환자를 아동 행동 평가 척도로 이해하는 폭을 넓혀보 고자 하였다. 또한 대상자의 고든 진단 기준(Gordon Diagnostic System, GDS)의 효율비(efficiency ratio)를 확인함으 로써 주의 집중력의 효율성이 자살 행동, 공격 행동과 어떠 한 관련이 있는지 알아보고자 하였다.

\section{방 법}

\section{1. 대 상}

본 연구는 2004년 4월부터 2015년 4월까지 삼성서울병원 정신건강의학과 병동에 입원한 10 세 이상 18 세 이하의 소아 청소년 환자를 대상으로 이루어졌다. 이 중 퇴원 시 최종 진 단이 Diagnostic and Statistical Manual of Mental Disorders, Fourth Edition, text revision에 근거하여 우울 장애 혹은 양 극성 장애의 기분 장애로 진단받은 환자를 대상으로 하며 입 원 기간 중, 혹은 입원 대기 중(입원 1달 이내) 심리검사를 시 행한 환자를 대상으로 하였다. 이 중 동반 질환으로 식이 장 애가 있거나 기질성 뇌 질환이 있는 경우는 동반 질환 자체 가 인지기능의 차이에 많은 영향을 미칠 것으로 판단하여 연 구에서 제외하였다. 또한 전체 평균 지능(Full Scale Intelligence Quotient, FSIQ)의 차이가 클 경우 특정 인지기능 차 이가 왜곡될 수 있다고 판단하여 $\mathrm{FSIQ}$ 가 85 이상 115 이하 인 대상자만을 포함시켰다. 연구는 삼성서울병원 임상연구윤 리위원회(Institutional Review Board)의 승인 후에 후향적 차 트 검토(retrospective chart review)를 통해 이루어졌다.

\section{2. 자살 행동 및 공격 행동의 정의}

후향적 차트 리뷰를 통하여 정신과 의사가 피험자의 입원 전 3개월 이내의 자살 행동 및 공격 행동 여부에 대해 판단 하였다. 자살 행동에는 자살 목적으로 제초제나 약물을 복 용하여 의료기관에 내원한 경우, 끈 등으로 목을 매거나, 차 가 다니는 대로에 누워 있거나, 뛰어내리려고 시도하거나, 상처 의 의료적 처치를 위해 의료기관에 내원한 경우 등 자살 의 도가 분명한 위험한 상황만을 포함하였다. 공격 행동은 텔레 비전이나 꽃병 등 깨졌을 때 사람이 다칠 수 있는 집기를 부 수거나, 다른 사람을 때리는 등 공격적인 행동이 다른 사람에 게 위험을 끼칠 수 있는 수준의 행동만을 포함하였다. 이를 통해 대상자를 자살 행동과 공격 행동이 모두 없는 군, 자살 행동군, 공격 행동군, 자살 행동과 공격 행동이 모두 있는 군 으로 나누었다.

\section{3. 인지기능 평가, 아동 행동 평가, 주의 집중력의 효율성 평가} 인지기능의 평가는 웩슬러 유아 지능 검사(Wechsler In- 
telligence Scale for Children, WISC)와 웩슬러 성인 지능 검사(Wechsler Adult Intelligence Scale, WAIS)로 이루어 졌다. WISC와 WAIS의 소검사 항목별로 각각 점수를 검토 하여, 특정 인지기능의 차이를 보고자 하였다. 연구가 이루어 진 삼성서울병원에서는 15 세까지 WISC, 16 세 이상은 WAIS 로 검사를 진행하였기에 연령을 두 군으로 나누어 평가하였 다. 연구 기간 중 WISC와 WAIS가 3판에서 4판으로 변화가 있었기에 우선 3판을 이용하여 검사받은 피험자와 4판을 이 용하여 검사받은 피험자를 따로 분석하였고, 이후에 판의 변 화에도 비슷하게 유지된 소검사 항목은 3판과 4판을 이용하 여 검사한 대상자를 합쳐서 분석을 진행하였다.

아동 행동 평가 척도는 Oh 등 ${ }^{21}$ 이 번안하여 1997년 출판 된 $\mathrm{K}-\mathrm{CBCL}$ 과 이후 개발되어 한국 표준화가 되어 출판된 $\mathrm{K}-\mathrm{CBCL}$ 6-182)을 이용하였으며, 주의 집중력의 효율성은 $\mathrm{GDS}^{23)}$ 의 효율비를 통해 확인하였다.

\section{4. 분석 방법}

대상자를 자살 및 공격 행동이 모두 없는 군, 자살 행동이 있는 군, 공격 행동이 있는 군, 자살 및 공격 행동이 모두 있 는 군의 네 군으로 나누어서 각 군 간 인구사회학적 특성 사 이에 차이가 있는지는 연속형 변수에 대해서는 각 군이 정규 분포를 따르지 않았으므로 크루스칼 왈리스의 일원분산방법 (Kruskal-Wallis test)을, 범주형 변수에 대해서는 피셔의 정 확 검정(Fisher's exact test)을 이용하여 분석하였다.

각 군이 WISC 혹은 WAIS의 소검사 항목 점수의 차이가 있는지를 봄으로써 인지기능의 어떤 특정 영역에서 차이가 있는지를 보고자 하였는데 각 군의 소검사 항목 점수가 정규 분포를 따르지 않았으므로 크루스칼 왈리스의 일원분산방법 에 따라 분석하였고, 터키 검정(Tukey test)을 실시하여 어느 군 간의 차이가 있는지 확인하였다. 우선 WISC와 WAIS의 3 판과 4판을 시행한 대상자를 따로 분석하였고, 판이 변하 여도 비슷하게 유지된 소검사 항목(WISC의 경우 공통성, 어 휘, 이해, 토막, 숫자, 기호 항목; WAIS의 경우에는 공통성, 어휘, 상식, 토막, 숫자, 산수, 기호 항목)에 대해서는 3판과 4 판의 구분 없이 분석을 시행하였다.

각 군 간에 아동 행동 평가 척도의 각 항목의 점수 차이가 있는지, GDS의 효율비의 차이가 있는지 여부도 크루스칼 왈 리스 일원분산방법으로 분석하였다.

통계적 유의성은 $\mathrm{p}<.05$ 인 경우로 하였고, 통계 분석은 SPSS ver.22(SPSS Inc., Chicago, IL, USA)로 수행하였다.

\section{결 과}

\section{1. 대상군의 인구사회학적 특징}

총 연구 대상군은 111 명이었으며 이 중 남자는 53 명, 여자 는 58명이었다. 검사 당시 총 대상군의 평균 연령은 $15.45 \pm$

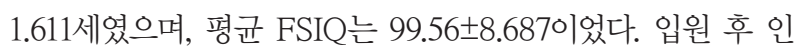
지 검사 시행까지 걸린 기간은 입원 전 21일부터 입원 후 32일

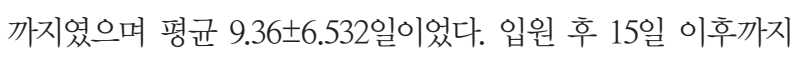
검사 시행이 이루어지지 않은 경우는 긴장형 양상(catatonic feature)을 보이거나 정신운동지연(psychomotor retardation) 이 있거나 공격적인 양상이 지속되어서 검사에 협조되지 않 은 경우였다.

양극성 장애 범주에 해당하는 대상군은 총 69명(62.2\%)이 었으며 이 중 제 1 형 양극성 장애가 22 명, 제 2 형 양극성 장애 가 12 명, 달리 분류되지 않는 양극성 장애가 35 명이었다. 우 울 장애 범주에 해당하는 대상군은 42명(37.8\%)이었으며 이 중 주요 우울 장애가 35 명, 기분 부전 장애가 4 명, 달리 분류 되지 않는 우울 장애가 3 명이었다. 정신건강의학과적 가족력 이 없는 경우는 62 명(55.9\%), 있는 경우는 47명(42.3\%)이었다. 자살의 가족력은 없는 경우가 100 명 $(90.1 \%)$, 자살 시도의 가 족력이 있는 경우가 5명(4.5\%), 완전 자살(complete suicide) 의 가족력이 있는 경우가 6명(5.4\%)이었다.

입원 전 3개월 이내에 자살 및 공격 행동이 모두 없는 군 은 67명(60.4\%), 자살 행동이 있는 군은 17명(15.3\%), 공격 행동이 있는 군은 24명(21.6\%), 자살 및 공격 행동이 모두 있 는 군은 3 명 $(2.7 \%)$ 이었다. 대상군의 입원 당시 기분 상태를 보 면, 자살 행동과 공격 행동이 모두 없는 군 67 명 가운데 조증 상태가 6명(9.0\%), 경조증 상태가 3명(4.5\%), 혼재형 상태가 20명(29.9\%), 우울 상태가 38명(56.7\%)이었다. 자살 행동이 있 는 군 17명 중에는 혼재형 상태인 경우가 2명(11.8\%), 우울 상 태인 경우가 15 명(88.2\%)이었다. 공격 행동이 있는 군 24명 가운데 조증 상태는 3명(12.5\%), 혼재형 상태는 12 명(50.0\%), 우울 상태는 9명(37.5\%)이었다. 자살 행동과 공격 행동이 모 두 있는 군 3명 가운데 조증 상태는 1명(33.3\%), 혼재형 상태 는 1명(33.3\%), 우울 상태는 1명(33.3\%)으로, 자살 행동을 보인 경우에 입원 당시 우울 상태인 경우가 높은 경향성을 보였다.

자살 행동군과 자살 행동과 공격 행동이 모두 있는 군을 합한 20명이 보인 자살 행동 중 약물 과다 복용은 8명(40.0\%), 목맴은 3명(15\%), 투신은 3명(15\%), 차도에 누워 있는 행동은 1 명 $(5 \%)$, 자해는 5 명 $(25 \%)$ 에서 있었다. 공격 행동군과 자살 행동과 공격 행동이 모두 있는 군을 합한 27명이 보인 공격 행동 중에 텔레비전, 꽃병 등 깨졌을 때 위험한 집기를 부순 
행동은 19명(70\%), 부모나 친구 등 타인을 때린 행동은 8명이는 Table 1에 제시하였다.

(30\%)에서 있었다.

총 연구 대상군 중 10 세에서 15 세 이하는 54 명이었고, 이

대상자의 자살 및 공격 행동에 따른 군 간의 인구사회학적, 중 Korean-WISC-3판(K-WISC-III)으로 검사한 군이 33명, 임상적 특징은 통계적으로 유의하게 차이가 있지 않았으며Ｋorean-WISC-4판(K-WISC-IV)으로 검사한 군이 21명이었

Table 1. Demographic and clinical data of participants (total $N=111$ )

\begin{tabular}{|c|c|c|c|c|c|c|}
\hline & $N G(N=67)$ & $S G(N=17)$ & VG $(N=24)$ & $\mathrm{BG}(\mathrm{N}=3)$ & $\chi^{2}$ & $\mathrm{p}$ \\
\hline Age, mean (SD) & $15.63(1.594)$ & $15.41(1.805)$ & $15.17(1.523)$ & $14.00(1.000)$ & 4.416 & .220 \\
\hline FSIQ, mean (SD) & $100.21(8.573)$ & $98.65(9.552)$ & $98.00(8.547)$ & $102.67(9.504)$ & 1.734 & .629 \\
\hline Diagnosis, N (\%) & & & & & 2.537 & .465 \\
\hline Bipolar disorders & $42(62.7)$ & $9(52.9)$ & $17(70.8)$ & $1(33.3)$ & & \\
\hline Depressive disorders & $25(37.3)$ & $8(47.1)$ & $7(29.2)$ & $2(66.7)$ & & \\
\hline Mood status, N (\%) & & & & & 14.900 & .052 \\
\hline Manic status & $6(9.0)$ & $0(0.0)$ & $3(12.5)$ & $1(33.3)$ & & \\
\hline Hypomanic status & $3(4.5)$ & $0(0.0)$ & $0(0.0)$ & $0(0.0)$ & & \\
\hline Mixed status & $20(29.9)$ & $2(11.8)$ & $12(50.0)$ & $1(33.3)$ & & \\
\hline Depressive status & $38(56.7)$ & $15(88.2)$ & $9(37.5)$ & $1(33.3)$ & & \\
\hline Sex, N (\%) & & & & & .882 & .878 \\
\hline Male & $32(47.8)$ & $7(41.2)$ & $12(50.0)$ & $2(66.7)$ & & \\
\hline Female & $35(52.2)$ & $10(58.8)$ & $12(50.0)$ & $1(33.3)$ & & \\
\hline Alcohol problem, N (\%) & & & & & .763 & .897 \\
\hline Yes & $6(9.0)$ & $1(5.9)$ & $1(4.2)$ & $0(0.0)$ & & \\
\hline No & $61(91.0)$ & $16(94.1)$ & $23(95.8)$ & $3(100.0)$ & & \\
\hline Game problem, N (\%) & & & & & 2.480 & .453 \\
\hline Yes & $11(16.4)$ & $5(29.4)$ & $5(20.8)$ & $1(33.3)$ & & \\
\hline No & $56(83.6)$ & $12(70.6)$ & $19(79.2)$ & $2(66.7)$ & & \\
\hline Residence, N (\%) & & & & & .977 & .858 \\
\hline Only in Korea & $51(76.1)$ & $12(70.6)$ & $19(79.2)$ & $2(66.7)$ & & \\
\hline Outside of Korea & $16(23.9)$ & $5(29.4)$ & $5(20.8)$ & $1(33.3)$ & & \\
\hline No. of hospitalization, N (\%) & & & & & 9.232 & .120 \\
\hline One & $61(91.0)$ & $14(82.4)$ & $23(95.8)$ & $2(66.7)$ & & \\
\hline Two & $5(7.5)$ & $3(17.6)$ & $0(0.0)$ & $1(33.3)$ & & \\
\hline Three & $0(0.0)$ & $0(0.0)$ & $0(0.0)$ & $0(0.0)$ & & \\
\hline Four & $1(1.5)$ & $0(0.0)$ & $1(4.2)$ & $0(0.0)$ & & \\
\hline School status, N (\%) & & & & & 9.385 & .467 \\
\hline Regular school & $53(80.3)$ & $14(87.5)$ & $16(66.7)$ & $2(66.7)$ & & \\
\hline Alternative school & $0(0.0)$ & $0(0.0)$ & $0(0.0)$ & $0(0.0)$ & & \\
\hline Leave of absence & $5(7.6)$ & $0(0.0)$ & $3(12.5)$ & $1(33.3)$ & & \\
\hline Drop out of school & $1(1.5)$ & $2(12.5)$ & $5(20.8)$ & $0(0.0)$ & & \\
\hline Psychiatric FHx, N (\%) & & & & & 1.263 & .760 \\
\hline Yes & $26(40.0)$ & $9(52.9)$ & $11(45.8)$ & $1(33.3)$ & & \\
\hline No & $39(60.0)$ & $8(47.1)$ & $13(54.2)$ & $2(66.7)$ & & \\
\hline Suicidal FHx, N (\%) & & & & & 6.102 & .345 \\
\hline Non & $61(91.0)$ & $15(88.2)$ & $21(87.5)$ & $3(100.0)$ & & \\
\hline Attempt FHx & $3(4.5)$ & $2(11.8)$ & $0(0.0)$ & $0(0.0)$ & & \\
\hline Complete suicide $\mathrm{FHx}$ & $3(4.5)$ & $0(0.0)$ & $3(12.5)$ & $0(0.0)$ & & \\
\hline Currently on medication, N (\%) & & & & & 2.341 & .542 \\
\hline Yes & $30(46.9)$ & $8(50.0)$ & $11(45.8)$ & $0(0.0)$ & & \\
\hline No & $34(53.1)$ & $8(50.0)$ & $13(54.2)$ & $3(100.0)$ & & \\
\hline
\end{tabular}

Kruskal-Wallis test was used for the analysis of continuous variables. Fisher's exact test was used for the analysis of nominal variables. BG: both suicidal/violent group, FHx: family history, FSIQ: Full Scale Intelligence Quotient, NG: non suicidal/violent group, SD: standard deviation, SG: suicidal group, VG: violent group 
Table 2. Mean differences of K-WAIS subtests' scores between adolescent mood disorder patients' behavior groups (age between 16 and 18 years old, $\mathrm{N}=33$ )

\begin{tabular}{|c|c|c|c|c|c|c|}
\hline & NG $(\mathrm{N}=22)$ & SG $(N=5)$ & VG $(N=6)$ & $\chi^{2}$ & $\mathrm{p}$ & \\
\hline Information, mean (SD) & $8.23(2.707)$ & $6.60(3.362)$ & $7.50(3.271)$ & 1.370 & .504 & \\
\hline Digit span, mean (SD) & $10.73(3.073)$ & $10.00(2.646)$ & $10.50(3.017)$ & .278 & .870 & \\
\hline Vocabulary, mean (SD) & $10.36(1.590)$ & $8.20(2.387)$ & $10.50(1.871)$ & 4.050 & .132 & \\
\hline Arithmetic, mean (SD) & $10.55(2.923)$ & $9.00(1.871)$ & $9.67(3.777)$ & 1.666 & .435 & \\
\hline Comprehension, mean (SD) & $11.27(2.292)$ & $7.20(2.168)$ & $9.67(3.204)$ & 8.454 & $.015^{*}$ & $N G>S G$ \\
\hline Similarities, mean (SD) & $9.73(3.042)$ & $9.40(2.608)$ & $8.33(4.274)$ & .410 & .815 & \\
\hline Picture completion, mean (SD) & $7.91(2.202)$ & $9.00(3.464)$ & $7.50(2.345)$ & 1.234 & .540 & \\
\hline Picture arrangement, mean (SD) & $10.14(1.910)$ & $10.80(2.280)$ & $11.33(2.338)$ & 1.051 & .591 & \\
\hline Block design, mean (SD) & $11.86(2.731)$ & $14.00(1.414)$ & $11.17(1.722)$ & 5.537 & .063 & \\
\hline Object assembly, mean (SD) & $6.36(5.123)$ & $4.20(5.762)$ & $5.67(6.408)$ & .310 & .857 & \\
\hline Digit-symbol coding, mean (SD) & $10.73(2.995)$ & $10.80(2.588)$ & $12.83(2.927)$ & 2.138 & .343 & \\
\hline
\end{tabular}

Kruskal-Wallis test was used for the analysis of continuous variables. Tukey test was used for post-hoc test. *: $p<.05$ was considered statistically significant. K-WAIS: Korean Wechsler Adult Intelligence Scale, NG: non suicidal/violent group, SD: standard deviation, SG: suicidal group, VG: violent group

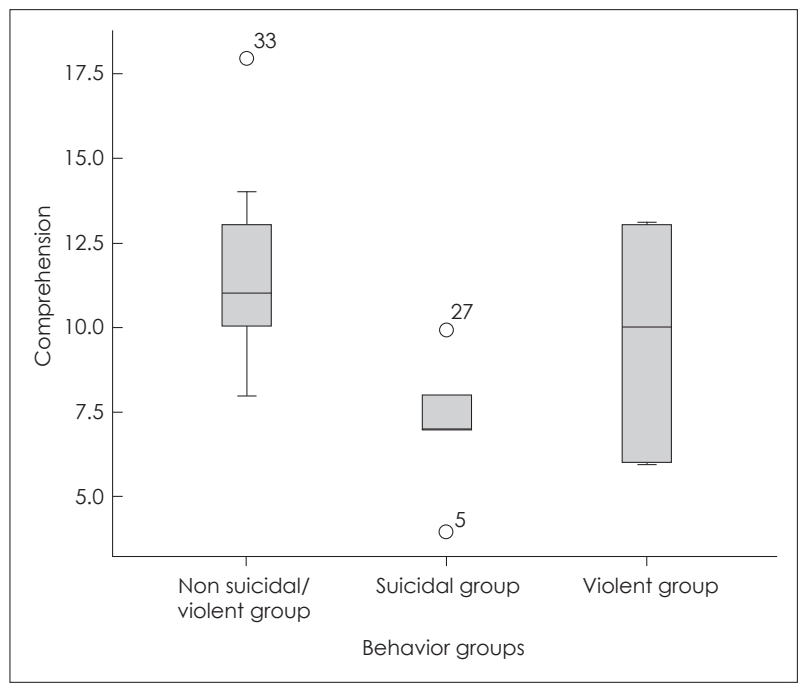

Fig. 1. K-WAIS comprehension subtest scores according to the adolescent behavior groups (age between 16 and 18 years old, N=33). K-WAIS: Korean Wechsler Adult Intelligence Scale

다. 16세 이상 18 세 이하는 57명이었고, 이 중 Korean-WAIS (K-WAIS)로 검사한 군이 33명, K-WAIS-4판(K-WAIS-IV) 으로 검사한 군이 24명이었다.

\section{2. 기분 장애 소아 청소년 환자의 자살 행동, 공격 행동과 인지기능과의 관계}

기분 장애 소아 청소년 환자의 자살 행동, 공격 행동과 인 지기능과의 관계는 크루스칼 왈리스 일원분산방법으로 확인 하였다. 우선 K-WISC-III를 시행한 군, K-WISC-IV를 시행 한 군, K-WAIS를 시행한 군, K-WIAS-IV를 시행한 군을 나누어 검사하였다.

이 중 K-WAIS를 시행한 군에서 이해 소검사 항목에서 세 군 간의 유의한 차이를 보였다 $\left(\chi^{2}=8.454, \mathrm{p}=.015\right)$. 터키 검정
결과 자살 행동군에서 자살 행동과 공격 행동이 없는 군에 비해 유의하게 이해 소검사 항목 점수가 낮음을 확인할 수 있었다(p=.008)(Table 2, Fig. 1). 또한 토막 소검사 항목에서 자살 행동군이 공격 행동군에 비해 점수가 높은 경향성이 나타났다 $\left(\chi^{2}=5.537, \mathrm{p}=.063\right)$ (Table 2). K-WISC-III, K-WISC$\mathrm{IV}, \mathrm{K}-\mathrm{WAIS}-\mathrm{IV}$ 검사를 시행한 경우에는 각 군 간 통계적으 로 유의한 지능 검사 소검사 항목 점수 간 차이가 관찰되지 않았다.

다음으로 K-WISC-III와 K-WISC-IV, K-WAIS와 KWAIS-IV를 시행한 대상군을 합쳐서 WISC인 경우에는 공 통 소검사인 공통성, 어휘, 이해, 토막, 숫자, 기호 항목에 대 해서, WAIS의 경우에는 공통성, 어휘, 상식, 토막, 숫자, 산 수, 기호 항목에 대해서 분석하였다. WISC군의 경우에는 통 계적으로 유의한 소검사 항목 점수 차이가 관찰되지 않았으 나 WAIS군에서는 토막 항목에서 유의한 점수의 차이가 관 찰되었다 $\left(\chi^{2}=7.496, \mathrm{p}=.024\right)$. 터키 검정에서 자살 행동군이 공 격 행동군에 비해 유의하게 점수가 높음을 확인할 수 있었다 ( $\mathrm{p}=.015)$ (Table 3, Fig. 2).

\section{3. 기분 장애 소아 청소년 환자의 자살 행동, 공격 행동과 아동 행동 평가 척도와의 관계}

기분 장애 소아 청소년 환자의 자살 행동, 공격 행동과 아 동 행동 평가와의 관계는 크루스칼 왈리스 일원분산방법과 터키 검정으로 확인하였다. 10세 이상 15 세 이하 대상자와, 16 세 이상 18 세 이하 대상자에서 따로 분석을 시행하였다.

이 중 10 세 이상 15 세 이하 대상자에서 아동 행동 평가 척 도를 시행한 39 명 가운데, 자살 행동과 공격 행동이 모두 없 는 군이 23명, 자살 행동이 있는 군이 4명, 공격 행동이 있는 군이 11 명, 자살 행동과 공격 행동이 모두 있는 군이 1 명이었 
Table 3. Mean differences of WAIS subtests' scores between adolescent mood disorder patients' behavior groups (age between 16 and 18 years old, $\mathrm{N}=57$ )

\begin{tabular}{|c|c|c|c|c|c|c|}
\hline & $N G(N=39)$ & $S G(N=8)$ & $\operatorname{VG}(N=10)$ & $\chi^{2}$ & $\mathrm{P}$ & \\
\hline Vocabulary, mean (SD) & $10.38(2.008)$ & $9.25(2.712)$ & $10.30(1.767)$ & 1.355 & .508 & \\
\hline Block design, mean (SD) & $10.97(2.805)$ & $13.00(2.070)$ & $9.30(2.983)$ & 7.496 & $.024^{*}$ & $S G>V G$ \\
\hline Information, mean (SD) & $9.00(2.575)$ & $8.50(3.964)$ & $8.10(2.961)$ & 1.016 & .602 & \\
\hline Digit span, mean (SD) & $10.59(2.807)$ & $11.25(2.915)$ & $9.60(2.797)$ & 1.854 & .396 & \\
\hline Arithmetic, mean (SD) & $10.54(2.694)$ & $11.00(3.117)$ & $9.80(3.706)$ & .212 & .900 & \\
\hline Similarities, mean (SD) & $10.44(2.614)$ & $10.25(2.964)$ & $8.70(3.773)$ & 2.543 & .280 & \\
\hline Digit-symbol coding, mean (SD) & $9.62(3.353)$ & $9.75(2.816)$ & $11.30(3.302)$ & 1.803 & .406 & \\
\hline
\end{tabular}

Kruskal-Wallis test was used for the analysis of continuous variables. Tukey test was used for post-hoc test. *: $p<.05$ was considered statistically significant. NG: non suicidal/violent group, SD: standard deviation, SG: suicidal group, VG: violent group, WAIS: Wechsler Adult Intelligence Scale

다. 자살 행동과 공격 행동이 모두 있는 군이 1 명밖에 없어서 통계 분석이 불가능하여 분석에서는 제외하였다. 이 중 공격 성, 외현화, 총 문제 항목에서 공격 행동군이 다른 두 군에 비해 통계적으로 유의하게 높은 점수를 보고하였음을 확인 할 수 있었다(공격성: $\chi^{2}=11.497, \mathrm{p}=.003$; 외현화: $\chi^{2}=9.605$, $\mathrm{p}=.008$; 총 문제: $\chi^{2}=6.870, \mathrm{p}=.032$ )(Table 4). 16세 이상 18 세 이하 대상자에서 아동 행동 평가 척도를 시행한 30 명 가운 데 자살 행동과 공격 행동이 모두 없는 군이 19명, 자살 행 동이 있는 군이 5명, 공격 행동이 있는 군이 6명이었다. 16세 이상 대상자에서는 각 군 간 통계적으로 유의한 아동 행동 평가 점수의 차이가 관찰되지는 않았으나 공격 행동군에서 공격성, 외현화, 총 문제의 평균 점수가 높이 측정되었다.

\section{4. 기분 장애 소아 청소년 환자의 자살 행동, 공격 행동과 주의 집중력의 효율성과의 관계}

기분 장애 소아 청소년 환자의 주의 집중력의 효율성은 $\mathrm{GDS}$ 의 효율비로 확인하였다. GDS를 시행한 환아 86명 중 자살 행동과 공격 행동이 모두 없는 군이 53명, 자살 행동이 있는 군이 13 명, 공격 행동이 있는 군이 19 명, 자살 행동과 공 격 행동이 모두 있는 군이 1 명이었다. 이 중 자살 행동과 공 격 행동이 모두 있는 군의 경우 1 명밖에 없었기 때문에 통계 분석에서는 제외하였다.

자살 행동, 공격 행동과 주의 집중력의 효율성과의 관계는 각 군의 고든 진단 기준 효율비가 정규분포를 따르지 않았기 에 크루스칼 왈리스 일원분산방법으로 확인하였고, 그 결과 군 간의 통계적으로 유의한 차이는 관찰되지 않았다 $\left(\chi^{2}=1.710\right.$, $\mathrm{p}=.425)$.

\section{고 찰}

본 연구에서 청소년 기분장애 환자는 자살 행동이나 공격 행동에 따라 이해 소검사 항목과 토막 소검사 항목의 유의한

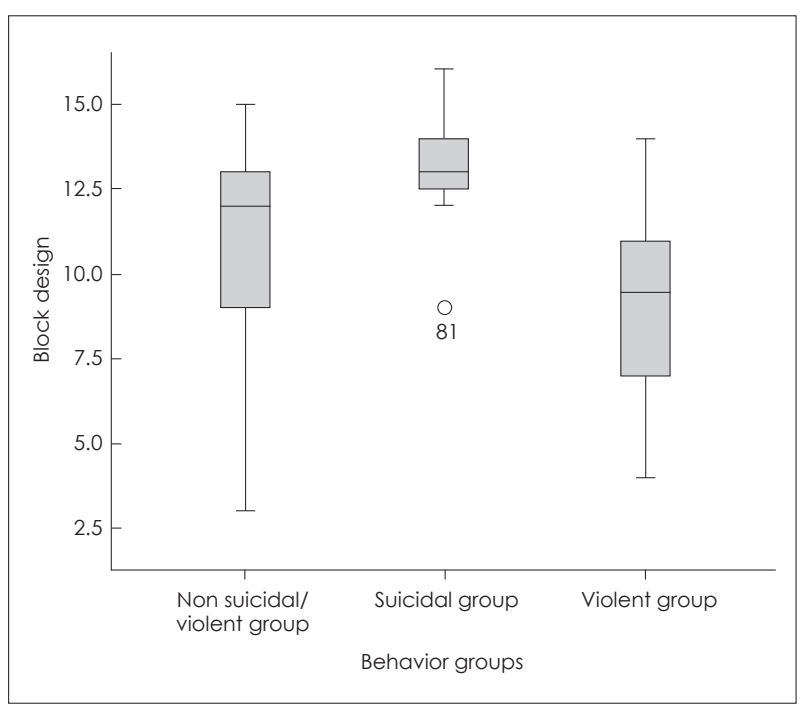

Fig. 2. WAIS block design subtest scores according to the adolescent behavior groups (age between 16 and 18 years old, $\mathrm{N}=57)$. WAIS: Wechsler Adult Intelligence Scale

차이를 보였으며 이는 일반적인 기분 장애 환자들에서 관찰 되지 않는 특성이었다. 첫째로 16 세 이상 18 세 이하의 청소년 기분 장애 환자에서 자살 행동을 한 군이 자살 행동이나 공 격 행동이 없는 군에 비해 $\mathrm{K}$-WAIS 이해 소검사 항목의 점 수가 유의하게 낮음을 알 수 있었다. K-WAIS의 이해 소검사 항목은 원칙(general principle)과 사회적 상황(social situation), 추상적 단어(abstract word)를 이해하고 판단하는 능 력을 평가하는 항목으로 사회적 상황을 왜곡할 때 낮아지는 항목이다. 따라서 자살 시도자들에서 사회적 상황을 왜곡하 여 해석하는 경향이 있다고 생각해 볼 수 있겠다.

이전 연구에서 자살자들에서 복측부 전전두엽 피질(ventrolateral prefrontal cortex)의 세로토닌 결합에 변화가 있었 음이 관찰되었고, ${ }^{24)}$ 최근의 이미지 연구에서도 자살 시도자 들에서 좌측 복측부 전전두엽 피질의 부피가 감소해 있음을 보고하고 있다. ${ }^{25)}$ 이를 통해 볼 때 뇌의 복측부 전전두엽 피 질이 자살 행동과 관련되었을 가능성이 높다고 볼 수 있겠 
Table 4. Mean differences of K-CBCL scores between child and adolescent mood disorder patients' behavior groups (age between 10 and 15 years old, $\mathrm{N}=38$ )

\begin{tabular}{|c|c|c|c|c|c|c|}
\hline & $N G(N=23)$ & $S G(N=4)$ & $\operatorname{VG}(\mathrm{N}=11)$ & $\chi^{2}$ & $p$ & \\
\hline Social, mean (SD) & $31.91(17.534)$ & $43.00(6.481)$ & $35.45(16.669)$ & 2.397 & .302 & \\
\hline School, mean (SD) & $47.87(12.230)$ & $48.00(4.629)$ & $44.82(13.571)$ & .529 & .768 & \\
\hline Activities, mean (SD) & $42.91(19.181)$ & $43.25(1.587)$ & $48.27(22.584)$ & .987 & .610 & \\
\hline Withdrawn/depressed, mean (SD) & $64.04(7.395)$ & $65.00(10.100)$ & $70.82(11.161)$ & 3.572 & .168 & \\
\hline Somatic complaints, mean (SD) & $59.91(8.571)$ & $52.25(16.112)$ & $62.55(15.188)$ & 1.473 & .479 & \\
\hline Anxious/depressed, mean (SD) & $66.22(8.426)$ & $65.75(3.500)$ & $71.64(11.902)$ & 2.039 & .361 & \\
\hline Social problems, mean (SD) & $61.87(8.971)$ & $57.50(5.447)$ & $66.09(8.093)$ & 3.426 & .180 & \\
\hline Thought problems, mean (SD) & $63.13(9.818)$ & $58.25(9.032)$ & $67.82(11.098)$ & 3.352 & .187 & \\
\hline Attention problems, mean (SD) & $62.74(7.593)$ & $62.00(8.485)$ & $65.45(8.825)$ & 1.105 & .576 & \\
\hline Rule-breaking behavior, mean (SD) & $63.78(11.229)$ & $60.25(11.413)$ & $70.82(5.862)$ & 4.836 & .089 & \\
\hline Aggressive behavior, mean (SD) & $61.04(8.488)$ & $53.00(14.306)$ & $71.91(8.117)$ & 11.497 & $.003^{*}$ & VG>NG, SG \\
\hline Internalizing problems, mean (SD) & $66.48(9.834)$ & $64.75(7.632)$ & $74.27(13.864)$ & 2.666 & .264 & \\
\hline Externalizing problems, mean (SD) & $63.43(11.086)$ & $55.75(13.500)$ & $75.82(9.745)$ & 9.605 & $.008^{*}$ & VG>NG, SG \\
\hline Total problems, mean (SD) & $66.91(8.929)$ & $61.50(4.041)$ & $75.55(11.579)$ & 6.870 & $.032 *$ & $V G>N G, S G$ \\
\hline
\end{tabular}

Kruskal-Wallis test was used for the analysis of continuous variables. Tukey test was used for post-hoc test. *: $p<.05$ was considered statistically significant. K-CBCL: Korea Child Behavior Checklist, NG: non suicidal/violent group, SD: standard deviation, SG: suicidal group, VG: violent group

다. Jollant 등 ${ }^{26}$ 의 연구에서는 자살 시도자들의 경우 화난 얼굴(angry faces)에 대해 대조군에 비해 유의하게 높은 복 측부 전전두엽 피질의 활성화를 보였다고 보고하고 있고, 이 는 자살 시도자들이 특히 부정적 환경에 민감하게 반응함을 시사한다고 볼 수 있으며, 따라서 환경을 부정적으로 왜곡할 가능성을 생각해 볼 수 있겠다. 또한 복측부 전전두엽 피질이 추상적 단어를 이해하는 데 역할을 하는 뇌의 부위라는 점에 서 ${ }^{27)}$ 자살 행동군에서 이해 소항목 검사 점수가 낮은 것을 알 수 있을 것이다. 15 세 이하 환자군에서는 자살 행동군에서 이러한 경향이 드러나지 않았는데 이는 발달상 사춘기 이전 에는 전전두엽 발달이 완전히 이루어진 시기가 아니기 때문 에, 이러한 자살 행동군의 신경인지학적 특징이 명확히 드러 나지 않은 것이라고 생각해 볼 수 있겠다. 이에 대해 명확히 이해하기 위해서는 추후에 더 많은 환자군을 대상으로 연령 별 혹은 사회적 연령별로 이러한 경향성의 차이가 있는지를 확인해 보는 연구가 필요할 것으로 생각된다.

둘째로 16 세 이상 18 세 이하 군에서 자살 행동군이 공격 행동군에 비해 WAIS 토막 소검사 항목의 점수가 유의하게 높음을 알 수 있었다. 토막 소검사 항목은 공간 능력(spatial ability)을 평가하는 검사로 알려져 있다. 이전 연구들에서 반 사회적 행동(antisocial behavior)을 보이는 군에서 어린 시절 시공간 능력의 저하(early visuospatial impairment)가 보고 된 경우가 있었다. 다른 연구들에서는 우측 측두엽(right temporal lobe)에 병변이 있는 환자에서 공간 능력이 저하되어 있음을 보고하였고 ${ }^{28)}$ 또 다른 연구에서는 공격 행동을 보이 는 사람들에서 측두엽 활동이 다름을 뇌파 검사를 통해 보
고하기도 하였다. 29,30) 이를 종합해 볼 때 우측 측두엽이 공격 행동과 공간 능력과 관련이 있음을 알 수 있겠다. 이를 통해 볼 때, 자살 행동군에서 토막 소검사 항목의 점수가 공격 행 동군에 비해 유의하게 높은 것은 자살 행동군의 경우 우측 측 두엽 기능이 잘 유지되고 있는 것을 의미한다고 볼 수 있고, 이 것이 공격성이 외부로 향하여 타인에 대한 공격 행동을 하는 것을 막아 주는 역할을 할 가능성에 대해 시사해 준다. 15 세 이하 대상군의 경우에는 이런 경향성이 나타나지 않았는데, 이는 앞서 언급한 바와 같이 아직까지 뇌 발달이 이루어지고 있는 시기이기 때문이라고 생각할 수 있겠다. 또한 15세 이하 에서는 자살 행동과 공격 행동을 모두 보이는 환아들이 있었 던 반면에, 16 세 이상에서는 자살 행동과 공격 행동을 모두 보이는 환아가 없었던 점은, 사춘기 초반까지는 공격성이 내 부로 향하는 것과 외부로 향하는 것이 구분되지 않고 있다가 이후에 뇌 발달과 더불어 그 방향성이 정해지는 것으로 생각 해 볼 수 있겠다. 그런 의미에서 볼 때, 뇌 발달 시기에 우측 측두엽 기능이 잘 유지될 경우, 공격성이 외부로 향하는 것을 막아 주는 역할을 할 가능성을 시사한다고 볼 수 있으며, 이 를 확인하기 위해서는 연령별 뇌 영상을 포함한 추후 연구가 필요할 것으로 생각된다.

본 연구에서는 10 세 이상 15 세 이하의 소아 청소년 환자군 에서는 공격 행동군에서 공격성, 외현화, 총 문제 점수가 통 계적으로 유의하게 높았다. 16세 이상 청소년군에서는 통계 적으로 유의한 차이는 보이지 않았으나 공격 행동군에서 공 격성, 외현화, 총문제 점수의 평균이 가장 높았다. 10 세에서 15 세 사이 대상군 수가 39 명이었던 데 비하여, 16 세에서 18 
세 이하의 대상군의 수가 30명밖에 되지 않았고, 각 군에 속 한 수가 19명, 5명, 6명밖에 되지 않았던 점을 미루어 볼 때 추후 대상군 수를 늘려 검사를 한다면 16세 이상에서도 공 격 행동군에서 더 많은 공격화, 외현화, 총 문제를 보고할 것 이라고 기대해 볼 수 있겠다. 이러한 점으로 미루어 볼 때, 아 동 행동 평가 척도의 공격성, 외현화, 총 문제 점수가 실제 공 격 행동을 예측하는 데 도움이 될 수 있을 것이라고 볼 수 있 겠다. 그러나 자살 행동군과 자살과 공격 행동이 모두 없는 군 사이에는 아동 행동 평가 척도의 항목 간 점수 차이가 없 었다.

주의 집중력의 효율성의 측면에서는, 각 군 간에 통계적으 로 유의미한 차이가 관찰되지 않았다. 이는 대상군이 모두 입원을 요할 정도의 심한 기분 장애 환자였기 때문일 것으로 생각되며, 건강한 대조군과 비교할 경우, 다른 결과를 보일 것으로 예상해 볼 수 있겠다.

본 연구의 강점으로는 대상군을 소아 청소년 기분 장애 환 자로 제한하여 보았기에, 기분 장애가 있는 환자군 내에서의 자살 행동, 공격 행동을 볼 수 있었다는 점을 들 수 있겠다. 또한 대상군의 $\mathrm{FSIQ}$ 를 85 에서 115 로 제한하여 군 간의 $\mathrm{FSIQ}$ 의 차이가 소검사 항목 검사 점수에 미치는 영향을 최소화하 였다.

또한 최근의 자살 행동, 공격 행동과 인지기능과의 관계를 보았고, 실제로 자살 행동이나 공격 행동의 위험도가 높은 군 만을 자살 행동군과 공격 행동군으로 분류한 점을 들 수 있겠 다. 즉, 대상군을 한정하여 연구를 진행함으로써 소아 청소년 기분 장애 환자에서 실제의 자살 행동, 공격 행동과 인지기능 의 특성을 확인할 수 있었던 점을 강점으로 볼 수 있겠다.

본 연구의 제한점으로는 우선 대상군의 수가 많지 않았다 는 점을 들 수 있다. 또한, 서울 소재 일대학병원에서만 이루 어진 연구이기에, 대상군의 인구학적 특징이 전체 기분 장애 소아 청소년 입원 환자군과 달랐을 가능성을 배재할 수 없겠 다. 따라서 추후에는 다기관에서 더 많은 환자군을 대상으로 하여 연구를 진행하는 것이 필요할 것으로 판단된다. 이와 더 불어 자살 행동이나 공격 행동의 심각도에 따른 인지기능의 차이의 변화를 확인하는 연구가 병행될 필요가 있겠다. 또한 후향적 차트 리뷰의 한계로 다른 연구에서 자살 행동, 공격 행동의 위험 인자로 알려진 아동 학대의 경험이나 또래 집단 에서의 따돌림 경험, 흡연력, 부모님의 결혼 상태 등의 위험 인자에 대한 집중적인 평가가 일반적인 평가에 비해 부족했 던 점을 본 연구의 제한점으로 볼 수 있겠다. 그리고 이미 이 루어진 검사를 통해 대상군의 인지기능을 평가하여야 했기 에 인지기능 평가 도구의 제한이 있었다. 향후에는 본 연구에 서 관련이 있다고 밝혀진 이해 능력과 공간 능력에 관련된
다양한 평가 도구를 사용하여 연구를 진행함으로써 기분 장 애 소아 청소년 환자의 자살 행동, 공격 행동과 관련된 인지 기능의 특성을 좀 더 자세히 알아볼 수 있을 것이다.

또한, 실제 환자들에게 도움이 되기 위하여 이해 능력과 관 련된 전측부 전전두엽의 훈련이나 공간 능력의 훈련을 통한 측두엽의 훈련이 추후 이들의 자살 행동이나 공격 행동에 영 향을 주는지 확인해 볼 필요가 있을 것이다.

\section{결 론}

본 연구에서는 16 세 이상 18 세 이하 청소년 기분 장애 환 자에서 자살 행동을 보인 경우, 자살 행동이나 공격 행동이 없는 군에 비해 이해 능력의 저하가 있음을 알 수 있었다. 또 한 공격 행동을 보인 경우 자살 행동을 보인 군에 비해 공간 능력이 저하되어 있음을 알 수 있었다.

중심 단어: 기분 장애· 소아 청소년 · 자살 행동 · 공격 행동 · 인지기능.

\section{Conflicts of Interest}

The authors have no financial conflicts of interest.

\section{References}

1) Sadock BJ, Sadock VA. Kaplan \& Sadock's synopsis of psychiatry: behavioral sciences/clinical psychiatry. 10th ed. Philadelphia: Lippincott Williams \& Wilkins;2007.

2) Merikangas KR, Jin R, He JP, Kessler RC, Lee S, Sampson NA, et al. Prevalence and correlates of bipolar spectrum disorder in the world mental health survey initiative. Arch Gen Psychiatry 2011; 68:241-251.

3) Kessler RC, Avenevoli S, Ries Merikangas K. Mood disorders in children and adolescents: an epidemiologic perspective. Biol Psychiatry 2001;49:1002-1014.

4) Rice BJ, Woolston J, Stewart E, Kerker BD, Horwitz SM. Differences in younger, middle, and older children admitted to child psychiatric inpatient services. Child Psychiatry Hum Dev 2002;32: 241-261.

5) Gould MS, Greenberg T, Velting DM, Shaffer D. Youth suicide risk and preventive interventions: a review of the past 10 years. J Am Acad Child Adolesc Psychiatry 2003;42:386-405.

6) Park S, Kim JW, Kim BN, Bae JH, Shin MS, Yoo HJ, et al. Clinical characteristics and precipitating factors of adolescent suicide attempters admitted for psychiatric inpatient care in South Korea. Psychiatry Investig 2015;12:29-36.

7) Stieben J, Lewis MD, Granic I, Zelazo PD, Segalowitz S, Pepler D. Neurophysiological mechanisms of emotion regulation for subtypes of externalizing children. Dev Psychopathol 2007;19:455-480.

8) Osler M, Nybo Andersen AM, Nordentoft M. Impaired childhood development and suicidal behaviour in a cohort of Danish men born in 1953. J Epidemiol Community Health 2008;62:23-28.

9) Keilp JG, Gorlyn M, Russell M, Oquendo MA, Burke AK, HarkavyFriedman J, et al. Neuropsychological function and suicidal behavior: attention control, memory and executive dysfunction in suicide attempt. Psychol Med 2013;43:539-551.

10) Jimenez-Treviño L, Blasco-Fontecilla H, Braquehais MD, Ceveri- 
no-Dominguez A, Baca-Garcia E. Endophenotypes and suicide behaviour. Actas Esp Psiquiatr 2011;39:61-69.

11) Séguin JR, Nagin D, Assaad JM, Tremblay RE. Cognitive-neuropsychological function in chronic physical aggression and hyperactivity. J Abnorm Psychol 2004;113:603-613.

12) Speltz ML, DeKlyen M, Calderon R, Greenberg MT, Fisher PA. Neuropsychological characteristics and test behaviors of boys with early onset conduct problems. J Abnorm Psychol 1999;108:315325.

13) Raine A, Yaralian PS, Reynolds C, Venables PH, Mednick SA. Spatial but not verbal cognitive deficits at age 3 years in persistently antisocial individuals. Dev Psychopathol 2002;14:25-44.

14) Stanford MS, Greve KW, Gerstle JE. Neuropsychological correlates of self-reported impulsive aggression in a college sample. Pers Individ Differ 1997;23:961-965.

15) Moffitt TE. The neuropsychology of juvenile delinquency: a critical review. Crime Justice 1990;12:99-169.

16) Morgan AB, Lilienfeld SO. A meta-analytic review of the relation between antisocial behavior and neuropsychological measures of executive function. Clin Psychol Rev 2000;20:113-136.

17) Gansler DA, McLaughlin NC, Iguchi L, Jerram M, Moore DW, Bhadelia R, et al. A multivariate approach to aggression and the orbital frontal cortex in psychiatric patients. Psychiatry Res 2009;171: 145-154.

18) Günther T, Holtkamp K, Jolles J, Herpertz-Dahlmann B, Konrad $\mathbf{K}$. Verbal memory and aspects of attentional control in children and adolescents with anxiety disorders or depressive disorders. J Affect Disord 2004;82:265-269.

19) Frías Á, Palma C, Farriols N. Neurocognitive impairments among youth with pediatric bipolar disorder: a systematic review of neuropsychological research. J Affect Disord 2014;166:297-306.

20) Martínez-Arán A, Vieta E, Reinares M, Colom F, Torrent C, Sánchez-Moreno J, et al. Cognitive function across manic or hypomanic, depressed, and euthymic states in bipolar disorder. Am J Psychiatry $2004 ; 161: 262-270$.
21) Oh K, Lee H, Hong K, Ha E. Korean child behavior checklist. Seoul: Chung Ang Aptitude;1997.

22) Oh K, Ha E. K-CBCL child behavior checklist. Seoul: Huno Consulting;2007.

23) Gordon M, Mettelman BB. The assessment of attention: I. Standardization and reliability of a behavior-based measure. J Clin Psychol 1988;44:682-690.

24) Arango V, Underwood MD, Gubbi AV, Mann JJ. Localized alterations in pre- and postsynaptic serotonin binding sites in the ventrolateral prefrontal cortex of suicide victims. Brain Res 1995;688: 121-133.

25) Ding Y, Lawrence N, Olié E, Cyprien F, le Bars E, Bonafé A, et al. Prefrontal cortex markers of suicidal vulnerability in mood disorders: a model-based structural neuroimaging study with a translational perspective. Transl Psychiatry 2015;5:e516.

26) Jollant F, Lawrence NS, Giampietro V, Brammer MJ, Fullana MA, Drapier D, et al. Orbitofrontal cortex response to angry faces in men with histories of suicide attempts. Am J Psychiatry 2008;165: 740-748.

27) Hoffman P, Jefferies E, Lambon Ralph MA. Ventrolateral prefrontal cortex plays an executive regulation role in comprehension of abstract words: convergent neuropsychological and repetitive TMS evidence. J Neurosci 2010;30:15450-15456.

28) Bohbot VD, Iaria G, Petrides M. Hippocampal function and spatial memory: evidence from functional neuroimaging in healthy participants and performance of patients with medial temporal lobe resections. Neuropsychology 2004;18:418-425.

29) Volkow ND, Tancredi L. Neural substrates of violent behaviour. A preliminary study with positron emission tomography. Br J Psychiatry 1987;151:668-673.

30) Wong MT, Lumsden J, Fenton GW, Fenwick PB. Electroencephalography, computed tomography and violence ratings of male patients in a maximum-security mental hospital. Acta Psychiatr Scand 1994;90:97-101. 